\title{
CONTAMINAÇÃO MICROBIOLÓGICA NO PERFIL DO SOLO POR ÁGUAS RESIDUÁRIAS
}

M. A. MORAIS, M. FERREIRA NETO, G. DE F. SILVA, R. B. DE LIRA, R. F. DE BRITO e L. C. V. MIGUEL

Universidade Rural do Semi-Árido alcilenemorais@ymail.com*

Artigo submetido em fevereiro/2015 e aceito em maio/2016

DOI: $10.15628 /$ holos.2016.2782

\section{RESUMO}

O presente trabalho teve como objetivo analisar a população de coliformes totais, termotolerantes e salmonella presentes no solo irrigado com efluente doméstico tratado. As amostras do solo foram coletadas nos meses de abril e setembro de 2012 , no período chuvoso e seco respectivamente, na área do cultivo do capim-elefante ( $P$. purpureum). As amostras foram feitas em 12 pontos aleatórios, nas linhas do plantio com profundidades de $0-0,40 \mathrm{~m}$. Em seguida, as amostras foram levadas ao Laboratório de Inspeção de Produtos de Origem Animal (LIPOA) da UFERSA, as amostras de coliformes foram analisadas pela técnica do Número Mais Provável por $100 \mathrm{~g}^{-1}$ (NMP $100 \mathrm{~g}^{-1}$ ) de coliformes totais e os termotolerantes (CTe). Para o isolamento de salmonella spp, utilizou-se a técnica de concentração por membrana filtrante, de $42 \mathrm{~mm}$ de porosidade por 142 $\mathrm{mm}$ de diâmetro. Não foram encontrados valores significativos da salmonella no solo irrigado no período chuvoso. Não foi observada a presença da bactéria Escherichia coli, quando considerado uma população menor que 3,0 NMP g-1. Não foram encontrados valores significativos da salmonela typhimurium no solo irrigado no período seco. Conclui-se que, os coliformes totais (CT) e termotolerantes (CTe) foram reduzidos acima de $60 \%$ nas duas primeiras amostras de solo nas profundidades de $0-0,2 m$ e $0,2-0,4 m$ e a qualidade da água residuária analisada é imprópria para utilização em irrigação de hortaliças que são consumidas cruas.

PALAVRAS-CHAVE: Salmonella, Coliformes, Efluente tratado.

\section{MICROBIOLOGICAL CONTAMINATION IN SOIL PROFILE FOR WASTE WATER}

\begin{abstract}
This study has aimed to analyze the population of total coliforms, thermotolerants and salmonella present in soil irrigated with treated domestic effluent. The soil samples were collected with a Dutch auger, in the months of April and September, 2012 in the rainy and dry season respectively, in the area of cultivation of napiergrass ( $p$. purpureum). The samples were made in 12 random points on the plantation lines with depths of $0-0.40 \mathrm{~m}$. Then, the sample were taken to the Animal Origins Products Inspection Laboratory (LIPOA) of UFERSA for microbiological contamination indicator. Coliform samples were analyzed by the Most Probable Number technique for $100 \mathrm{~g}-1$ (NMP $100 \mathrm{~g}$-1) of total coliforms and thermotolerants (CTe) were performed by multiple
\end{abstract}

tubes MPN technique. For the isolation of salmonella spp it was used the concentration technique for membrane filter, $42 \mathrm{~mm}$ of porosity by $142 \mathrm{~mm}$ of diameter. There were no significant amounts of salmonella in irrigated soil in the rainy season. It was observed the presence of Escherichia coli bacteria, when considered a smaller population than $3.0 \mathrm{NMP} \mathrm{g}^{-1}$. There were no significant amounts of salmonella typhimurium in soil irrigated in the dry season. In conclusion, total coliforms (TC) and thermophilic (CTe) were reduced over $60 \%$ in the first two soil samples at depths of $0-0,2 \mathrm{~m}$ and $0,2-0,4 \mathrm{~m}$ and quality of wastewaters analyzed is unfit for use in irrigation of vegetables that are consumed raw.

KEYWORDS: Salmonella, Coliform, Treated effluent. 


\section{INTRODUÇÃO}

A utilização de efluentes de esgotos domésticos tratados tem se mostrado uma alternativa promissora para o desenvolvimento social e econômico da região, podendo assim incentivar a permanência dos agricultores nas pequenas áreas rurais, bem como contribui para minimizar as migrações para os grandes centros urbanos. Contudo o risco da dispersão de coliformes fecais e de outras bactérias pode ser minimizado se houver um manejo adequado do esgoto sanitário.

A contaminação do solo por coliformes fecais se constitui indicativo da contaminação por outros microrganismos patológicos tais como vírus e bactérias. (VAN CUYK et al., 2001).

Na região semiárida do nordeste brasileiro, onde a media pluviométrica anual é de pouco mais de $700 \mathrm{~mm}$ e concentrada em 4 a 6 meses do ano Blake et al., (2005) a água é um recurso escasso que reflete na produtividade agrícola e em particular atinge os pequenos agricultores que não tem fontes alternativas para manter suas culturas durante as estiagens. Os reflexos são sentidos na agricultura das pequenas propriedades, que dependem das chuvas como única fonte hídrica bem sucedida.

Do ponto de vista da irrigação, o reuso de água exige uma gestão mais complexa da prática e um monitoramento mais restrito dos procedimentos, quando o reuso é comparado ao uso de uma água com melhor qualidade, ao qual normalmente se utiliza nessa prática, Alguns cuidados devem ser adotados visando não poluir o solo e os recursos hídricos, bem como preservar a saúde do próprio irrigante (EMBRAPA, 2009).

Além disso, o esgotamento sanitário feito de forma inadequado afeta diretamente a saúde e a qualidade de vida das populações, onde doenças infecciosas continuam sendo uma importante causa de mortalidade (BRASIL, 2012).

O esgoto contém inúmeros organismos vivos, tais como bactérias, vírus, vermes e protozoários que na sua maioria são depositados junto com os dejetos humanos. Contém ainda, inúmeros organismos vivos (bactérias, vírus, vermes e protozoários) que em sua maioria, são liberados juntos aos dejetos humanos. Alguns são de suma importância, pois decompõem a matéria orgânica complexa, transformando-a em compostos orgânicos mais simples e estáveis; outros, denominados organismos patogênicos são causadores de doenças (BRAGA, et al.; 2005).

O solo apresenta grande capacidade de decompor ou inativar materiais potencialmente prejudiciais ao ambiente, por meio de reações químicas e de processos microbiológicos. Essa disposição de água residuária no sistema solo-planta, quando feita sem critérios agronômicos e ambientais, pode causar problemas de contaminação do solo, das águas superficiais e subterrânea e toxicidade às plantas; por outro lado, se bem planejada essa aplicação pode trazer benefícios tais como: fonte de nutrientes e água para plantas, redução do uso de fertilizantes e do seu potencial poluidor (ERTHAL et al., 2010).

Os fatores que justificam o uso de águas residuárias são a conservação da água disponível, sua grande disponibilidade, possibilidade do aporte e reciclagem de nutrientes (reduzindo a necessidade de fertilizantes minerais sintéticos - químicos), permitindo a preservação do ambiente. (VAN DER HOEK et al., 2002). 
Este trabalho objetiva analisar a população de coliformes totais, termotolerantes e Salmonella presentes no solo irrigado com efluente doméstico tratado.

\section{MATERIAL E MÉTODOS}

Este trabalho foi conduzido na unidade experimental de reuso da água de área comunitária de uso agrícola, pertencente ao Projeto do Assentamento Milagre, no município de Apodi/RN.

De acordo com a classificação de Köppen, o clima predominante na região é do tipo BSw' $h^{\prime}$, caracterizado por ser muito quente, seco e salubre, tendo predominância do clima semiárido, inserido no bioma caatinga. A temperatura máxima é de $37^{\circ} \mathrm{C}$ e mínima de $21^{\circ} \mathrm{C}$, com períodos chuvosos variando de janeiro a julho e seco de julho a dezembro. Os meses em que ocorrem as maiores precipitações são março a abril. Com média anual oscilando em torno de 600 e $700 \mathrm{~mm}$, Insolação média da região é de aproximadamente 3041 horas ano, com evaporação média de 2190 mm ano, Azevedo et al.,(2013) O solo recebeu a classificação de argissolo vermelho amarelo, conforme (EMBRAPA 2009).

Para analisar a contaminação microbiológica no perfil do solo e do efluente, foram coletadas amostras do efluente tratado e do solo nos meses de abril e setembro de 2012, no período chuvoso e seco respectivamente, na área do cultivo do capim-elefante ( $P$. purpureum) irrigada com água residuária de origem doméstica.

As amostras do efluente tratado foram coletadas na caixa de saída do reator da Estação de Tratamento de Esgoto, coletadas em frascos estéreis e acondicionado em caixa térmico a 4으. As amostras do solo foram coletadas com trado holandesas, em seguida colocadas em sacos plásticos estéreis. Esta foi feita em 12 pontos aleatórios, nas linhas do plantio com profundidades de 0 - 0,40 $m$, em cada duas coletas simples para formar uma composta.

Em seguida as amostras do efluente e do solo foram levadas ao Laboratório de Inspeção de Produtos de Origem Animal (LIPOA) da UFERSA, para análise da salmonela e coliformes para avaliar o indicador de contaminação microbiológica.

As análises do efluente consistia na retirada de uma alíquota de $10 \mathrm{ml}$ diluída em $90 \mathrm{~mL}$ de solução salina Em seguida, retirava-se $1 \mathrm{~mL}$ dessa primeira diluição, inserindo em um tubo de ensaio contendo $9 \mathrm{~mL}$ da s. salina, repetindo esse último procedimento para o terceiro tubo. De cada diluição retirava-se $1,5 \mathrm{~mL}$, depositando $0,5 \mathrm{~mL}$ em cada tubo de verde brilhante (meio de cultura seletivo para coliformes totais), totalizando 3 tubos de cada diluição. Em seguida o material seguia para o banho-maria a $36 \circ \mathrm{C}$ com variação \pm 1 으, por $48 \mathrm{~h}$. Os tubos continham um tubo de Duran que captava todo o gás produzido pelas bactérias presentes na diluição. Caso não houvesse bactérias, não haveria gás no tubo, sendo este negativo para a presença de coliformes totais, não passando para a próxima etapa. Os tubos que apresentasse positivo nesse primeiro meio seriam inoculados em um segundo meio de cultura, o EC (seletivo para coliformes termotolerantes), sendo levados ao banho-maria a 45 으 por $48 \mathrm{~h}$. Os tubos que apresentassem gás no tubo de Duran seriam positivos para Escherichia Coli.

Para o isolamento de salmonella spp, utilizou-se a técnica de concentração por membrana filtrante, de $42 \mathrm{~mm}$ de porosidade por $142 \mathrm{~mm}$ de diâmetro. A membrana contendo o concentrado foi submetida à pré-enriquecimento em Água Peptonada Tamponada (APT), que foi incubada a $37^{\circ}$ 
$\mathrm{C} / 24$ horas, seguida pelo enriquecimento em Caldo Rappaport-Vassiliadis ( $37^{\circ} \mathrm{C} / 24$ e 48 horas) e em Caldo Selenito-novobiocina, $\left(42^{\circ} \mathrm{c} / 24,48,120\right.$ horas). 0 isolamento foi feito em meios seletivos: Agar Xilosa Lisina Descarboxilase (XLD) e Ágar Verde Brilhante (VB). As colônias com crescimento típico de Salmonella (no XLD escolheram-se as colônias vermelhas com centro preto, e no VB as colônias avermelhadas) foram submetidas à identificação bioquímica (TSI, SIM, Uréia Citrato, Vermelho de Metila e Voges Proskauer -MV/VP, descarboxilação da lisina, e fenilalanina).

As análises do solo foram avaliadas pela técnica do Número Mais Provável por $100 \mathrm{~g}^{-1}$ (NMP $100 \mathrm{~g}^{-1}$ ) para coliformes totais e termotolerantes (CTe) descrita em Macedo (2003), também conforme a Instrução Normativa 62, do Ministério da Agricultura, Pecuária e Abastecimento MAPA (2003). Foi determinada a quantidade de coliformes totais, coliformes termotolerantea (Escherichia coli) e salmonela spp, por grama de solo.

Para análise de coliformes presentes no solo seguiu-se o mesmo procedimento anterior, porém ao invés de utilizar solução salina, utilizou-se água peptonada, sendo a primeira diluição pesado $25 \mathrm{~g}$ de solo e depositados em um frasco com $225 \mathrm{ml}$ da água peptonada (Figura 1). Colocava-se o solo imerso na água em um saco estéril para homogeneização. Depois se retirava alíquota de $1 \mathrm{~mL}$ da solução e depositando em um tubo contendo $9 \mathrm{~mL}$ da água, repetindo para um terceiro tudo. Utilizaram-se os mesmos meios de cultura e procedimentos de determinação de coliformes. Para o isolamento de salmonella spp, presente no solo, utilizou-se a técnica de concentração por membrana filtrante, de $42 \mathrm{~mm}$ de porosidade por $142 \mathrm{~mm}$ de diâmetro descrito para analise do efluente tratado.

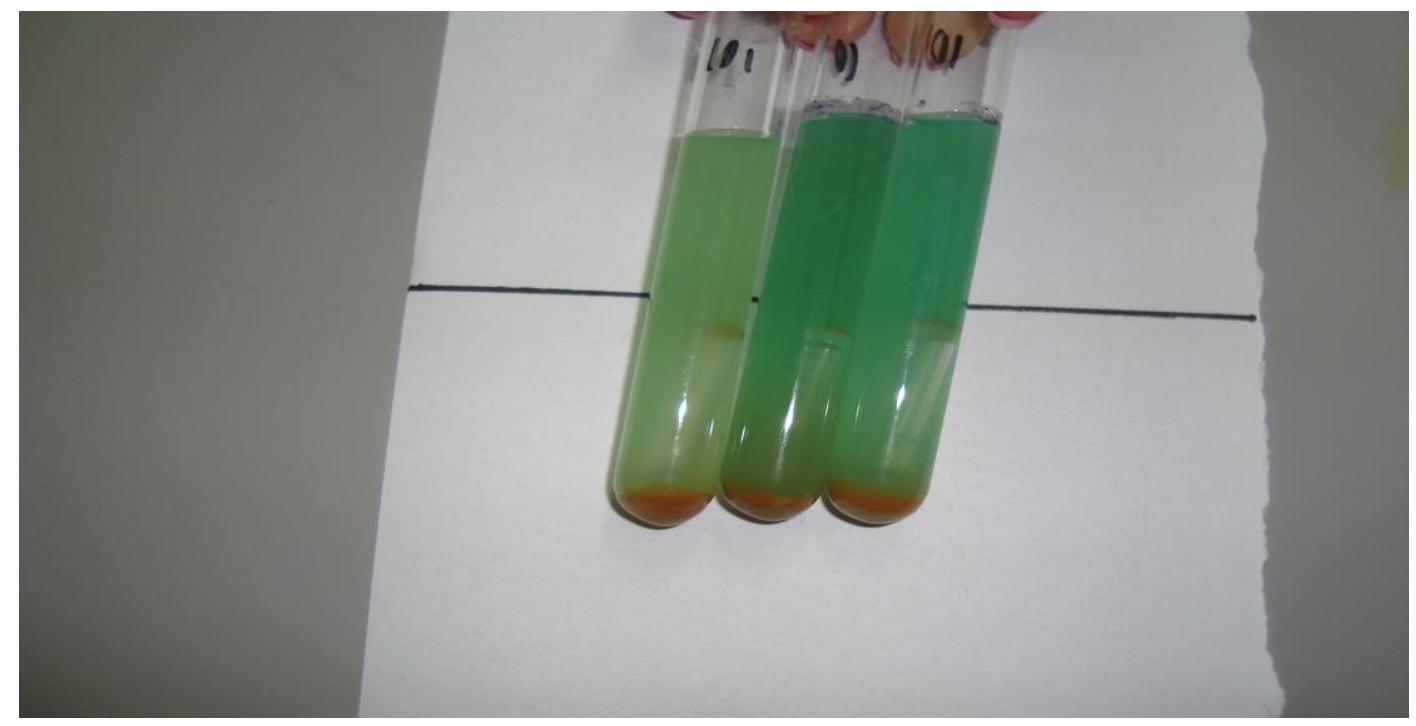

Figura 1: Análise do solo com enriquecimento em Caldo Rappaport-Vassiliadis, realizado na UFERSA.

\section{RESULTADOS E DISCUSSÃO}

Com os resultados obtidos observou-se na tabela 1 grande variação na população de coliformes totais e termotolerantes, sendo ambos analisados na mesma profundidade no solo, de acordo com os pontos de coleta pré-determinados. Na Tabela 1 são apresentados os resultados da análise microbiológica feita para coliformes e salmonella ssp no solo e nas águas residuária no experimento para irrigação no período chuvoso. 
Tabela 1: Análise de coliformes totais, termotolerantes e salmonellas presentes no solo e na água utilizados para o cultivo de capim elefante no período chuvoso.

\begin{tabular}{cccc}
\hline Pontos de coleta & $\begin{array}{c}\text { Coliformes Totais } \\
\text { (NMP/g ou } \mathbf{~ L )}\end{array}$ & $\begin{array}{c}\text { Coliformes } \\
\text { Termotolerantes } \\
\text { (NMP/g ou } \mathbf{~ L})\end{array}$ & Salmonella ssp. \\
\hline 1 & 1100 & 9,2 & Ausência \\
\hline 2 & 150 & 3,6 & Ausência \\
\hline 3 & 240 & 4,3 & Ausência \\
\hline 4 & 23 & $>3,0$ & Ausência \\
\hline 5 & $>1100$ & 150 & Ausência \\
\hline 6 & 9,2 & 3,0 & Ausência \\
\hline Água & & Ausência \\
\hline
\end{tabular}

Nota-se que há bastante variação entre pontos de solo coletados, tanto na população de coliformes totais quanto de coliformes termotolerantes, sendo ambos analisados na mesma profundidade. Esses fatos podem ser atribuídos à baixa uniformidade de infiltração do efluente aplicado, pois o acúmulo de água na superfície do solo e o sombreamento provocado pelo capim contribuíram para a sobrevivência das bactérias no solo com baixa infiltração, como ocorre com o argissolo, onde há maior acúmulo de efluente nas camadas superficiais, resultando em um maior nível populacional de bactérias (SUKIAS e NGUYEN, 2003).

Corroborando com o autor Salvucci (2009), quando afirma que a capacidade de produzir biofilme em Escherichia coli e Salmonella spp. são semelhantes entretanto, a salmonella spp., possui uma menor capacidade de retenção no solo o que eleva o risco de infiltração, transporte por escoamento ou de contaminação de águas subterrâneas.

De acordo com a metodologia utilizada, não foi observada a presença da bactéria Escherichia coli, quando considerado uma população menor que 3,0 NMP g-1 (Número Mais Provável $\mathrm{g}^{-1}$ ), segundo a Instrução Normativa 62 (MAPA, 2003) que considera população menor que 3,0 NMP g ${ }^{-1}$ como equivalente à ausência de Escherichia coli.

Todavia os demais valores apresentaram resultados contrários de acordo com Ceará (2002), os valores médios de coliformes totais $\left(1.100,0 \mathrm{NMP} 100 \mathrm{~mL}^{-1}\right)$ e coliformes termotolerantes (290,0 NMP $100 \mathrm{~mL}-1)$ foram bem inferiores ao valor de $5.000 \mathrm{NMP} 3865 \mathrm{~mL}^{-1}$. Assim sendo, o efluente atende as recomendações para reuso da água em culturas não consumidas cruas, onde o nível populacional de coliforme termotolerantes deve ser inferior a 5000 NMP 100 $\mathrm{mL}$.

Por conseguinte a sobrevivência dos microrganismos no solo, na água indica uma instabilidade significativa na resistência aos desafios ambientais. Agentes patogênicos sobrevivem mais tempo, respectivamente, na água e no solo em temperaturas mais baixas Guan et al.,(2003), Escherichia coli, pode sobreviver por até 10 semanas, e multiplicar-se em temperaturas de 22 a 37 ${ }^{\circ} \mathrm{C}$ e quando depositada no solo, Escherichia coli, pode sobreviver, reproduzir e mover-se por um período de até dois meses, podendo gerar contaminação do lençol freático por lixiviamento (ELVING, 2009).

Em comparação com a população de coliformes presentes na água, o solo se mostrou como filtro, pois a redução ocasionada é de quase $100 \%$, principalmente para coliformes termotolerantes, em que a população foi menor do que os coliformes totais. 
Corroborando com Oliveira e Urbinati (2013), que utilizaram efluente de suinocultura no cultivo de milho, onde constataram decaimento da população de coliformes presentes na água após o lançamento no solo. Em conformidade com os limites estabelecidos Portaria no 154 do Estado do Ceará (CEARÁ, 2002), assim sendo, o efluente atende as recomendações para reuso da água em culturas não consumidas cruas, onde o nível populacional de coliforme termotolerantes deve ser inferior a $5000 \mathrm{NMP} 100 \mathrm{~mL}^{-1}$.

Não foram encontrados valores significativos da salmonella no solo irrigado no período chuvoso. Trabalho desenvolvido por Plachá et al., (2001), ao tratar da sobrevivência da salmonella typhimurium no solo, mostrou que essa bactéria é afetada pela temperatura.

Observa-se grande variação na população de coliformes totais e termotolerantes, sendo ambos analisados na mesma profundidade no solo, de acordo com os pontos de coleta prédeterminados. Na Tabela 2 são apresentados os resultados da análise microbiológica feita para coliformes e salmonella spp no solo e nas águas residuária no experimento para irrigação no período seco.

Tabela 2. Análise de coliformes totais, termotolerantes e salmonelas spp presentes nas águas residuária e no solo, para camada $0-40 \mathrm{~cm}$, em período seco.

\begin{tabular}{cccc}
\hline Pontos de coleta & $\begin{array}{c}\text { Coliformes Totais } \\
\text { (NMP/g ou mL) }\end{array}$ & $\begin{array}{c}\text { Coliformes Termotolerantes } \\
\text { (NMP/g ou mL) }\end{array}$ & Salmonella spp. \\
\hline 1 & $75 \mathrm{NMP} / \mathrm{g}$ & $>3,0 \mathrm{NMP} / \mathrm{g}$ & Ausência \\
\hline 2 & $460 \mathrm{NMP} / \mathrm{g}$ & $3,6 \mathrm{NMP} / \mathrm{g}$ & Ausência \\
\hline 3 & $<3 \mathrm{NMP} / \mathrm{g}$ & $4,2 \mathrm{NMP} / \mathrm{g}$ & Ausência \\
\hline 4 & $9,2 \mathrm{NMP} / \mathrm{g}$ & $<3,0 \mathrm{NMP} / \mathrm{g}$ & Ausência \\
\hline 5 & $3,6 \mathrm{NMP} / \mathrm{g}$ & $<3,0 \mathrm{NMP} / \mathrm{g}$ & Ausência \\
\hline 6 & $3,6 \mathrm{NMP} / \mathrm{g}$ & $<3 \mathrm{NMP} / \mathrm{g}$ & Ausência \\
\hline Água & $>1100 \mathrm{NMP} / \mathrm{mL}$ & Ausência \\
\hline
\end{tabular}

Portanto, a sobrevivência dos organismos patogênicos depende de fatores como luz solar, temperatura e umidade relativa do ar, entre outros (SOARES et al. 2006).

Não foram encontrados valores significativos da salmonela typhimurium no solo irrigado no período seco. Plachá et al. (2001), relatam a sobrevivência da Salmonella typhimurium por 85 dias nas estações mais frias (outono/inverno) e por 26 dias no verão. Para Paganini, (2003) A Escherichia coli e Salmonella spp sobrevivem até dez dias, após a última irrigação.

Diante disso, a alta temperatura e a baixa umidade do solo, justificada pela temperatura do solo e a estação seca da região semiárida no período seco, provavelmente favoreceu a eliminação de salmonella typhimurium.

Em geral, a temperatura em países de clima quente varia entre 30 a $35^{\circ} \mathrm{C}$. Segundo Metcalf e Eddy (2003), a faixa de temperatura considerada ideal, para as atividades microbianas no tratamento de esgoto, varia de 25 a $35^{\circ} \mathrm{C}$. 


\section{CONCLUSÃO}

- Os coliformes totais (CT) e termotolerantes (CTe) foram reduzidos acima de $60 \%$ nas duas primeiras amostras de solo nas profundidades de $0-0,2 \mathrm{~m}$ e $0,2-0,4 \mathrm{~m}$.

- Verificou-se a eliminação de Salmonella typhimurium no solo e no efluente em ambos períodos.

- Observou-se que a qualidade da água residuária analisada é imprópria para utilização em irrigação de hortaliças que são consumidas cruas

\section{REFERÊNCIAS BIBLIOGRÁFICAS}

1. AZEVEDO, J.; DUTRA, I.C.B.; COSTA, F.G.B.; BATISTA, R.O.; COSTA, L.R. Alterações químicas de cambissolo irrigado com água residuária domestica tratada. Revista Agropecuária Cientifica no Semiárido. V.9, n.2, p. 66-76, abr-jun, 2013

2. BRAGA, B.;HESPANHOL, I.; CONEJO,J. G. L. Introdução à Engenharia Ambiental. 2edição. Ed. Vol. V. Pearson Prentice Hall, 2005. 318p.

3. BRASIL. CENTRO DE GESTÃO E ESTUDOS ESTRATÉGICOS. A questão da água no Nordeste. Brasília: CGEE, 2012.436p

4. BLAKE. C.D.M.; KÖNIG, A.; GHEYI, H.R.; CEBALLOS, B.S.O. Aspectos nutritivos e sanitários do capim elefante irrigados com diferentes lâminas de agua residuária domestica. In: Anais... 23으 Congresso Brasileiro de Engenharia Sanitária e Ambiental. Campo Grande- MS. 2005

5. CEARÁ. SECRETARIA DE MEIO AMBIENTE DO ESTADO DO CEARÁ. Portaria n.ำ154/2002, Dispõe sobre os padrões e condições para lançamento de efluentes líquidos gerados por fonte poluidora.

http://antigo.semace.ce.gov.br/integracao/biblioteca/legislacao/conteudo_legislacao.asp?cd =95 4 Fev. 2014.

6. EMPRESA BRASILEIRA DE PESQUISA AGROPECUÁRIA-EMBRAPA. Manual de métodos de análise de solo. 2. ed. Brasília: Embrapa Informação Tecnológica, 2009. 624 p.

7. ERTHAL, V.J.T.; Ferreira, P.A.; Matos, A.T.; Pereira, O.G. Alterações físicas e químicas de um Argissolo pela aplicação de água residuária de bovinocultura. Revista Brasileira de Engenharia Agrícola e Ambiental, v.14, p.467-477, 2010.

8. ELVING, J. Pathogen Inactivation and Regrowth in Organic Waste during Biological Treatment. Department of Chemistry, Environment and Feed Hygiene, National Veterinary Institute. (SVA), SE-751 89, 2009.

9. GUAN, T.Y.; HOLLEY, R.A. Pathogen survival in swine manure environments and transmission of human enteric illness-A Review. Journal Environmental Quality, v.32, p.383-391, 2003.

10. MACÊDO, J.A.B. de. Métodos laboratoriais de análises físico-químicas e microbiológicas. 2.ed. Belo Horizonte: Conselho Regional de Química, 2003. 450p

11. MAPA-Ministério da Agricultura, Pecuária e Abastecimento. Instrução Normativa № 62, de 26 de agosto de 2003.Disponível em: <http://www.agricultura.gov.br/consultasislegis>. Acesso em: 28 de abril. 2013. 
12. OLIVEIRA, R. A. de: UBINARTE, E. "Coliformes totais e termotolerantes no solo fertirrigado com água residuárias de suinocultura em reatores aeróbio. In: III SYMPOSIO ON AGRICULTURA AND AGROINDUSTRIAL WASTE MANAGEMENT v5. 2013. Anais. SAO PEDRO, SP.

13. PAGANINI, W. S. Reúso de água na agricultura. In: Mancuso, P. S. S.; Santos, H. F. (ed) Reúso de água. Barueri: Manole, 2003. p.338-401.

14. PLACHÁ, I.; VENGLOVSKÝ, J.; SASÁKOVÁ, N.; SVOBODA, I.F. The effect of summer and winter seasons on the survival of Salmonella typhimurium and indicator micro-organisms during the storage of solid fraction of pig slurry. Journal of Applied Microbiology; p.1036-1043, 2001.

15. SALVUCCI, A. E.; ZHANG, W.; MORALES, V.L.; ÇAKMAK, M.E.; HAY, A.G.T.S. The impact of biofilm-forming potential and tafi production on transport of environmental Salmonella through unsaturated porous media. Revista de Biologia, 64, 460-464, 2009.

16. SOUSA, J. T. de.; CEBALLOS, B. S. O. de.; HENRIQUE, I. N.; Dantas, J. P.; LIMA, S. M. S. Reúso de água residuária na produção de pimentão (Capsicum annuum L.). Rev. bras. eng. agríc. ambient. vol.10 no.1 Campina Grande Mar. 2006

17. SUKIAS, J. P. S.; NGUYEN, M. L. Inactivation of E. coli in riparian and non-riparian soils. In: DIFFUSE

18. VAN CUYK, S.; SEIGRIST, R.; LOGAN, A.; MASSON, S.; FISCHER, E.; FIGUEROA, L. Hydraulic and purification behaviors and their interactions during wastewater treatment in soil infiltration systems. Water Resources, v. 35, n. 4, p. 953-964, 2001.

19. VAN DER HOEK, W.; Hassan, U.M.; Ensink, J.H.J.; Feenstra, S.; Raschid-Sally, L.; Munir, S.; Aslam, R.; Alim, N.; Hussain, R.; Matsuno, Y. Urban wastewater: a valuable resource for agriculture. A case study from Horoonabad, Pakistan. Colombo, Sri Lanka: International Water Management Institute, p. 29, 2002. 